\title{
Look After Your Heart programme: impact on health status, exercise knowledge, attitudes, and behaviour of retired women in England
}

\author{
Linda Rowland, Edward J Dickinson, Penny Newman, Dominic Ford, Shah Ebrahim
}

\begin{abstract}
Objectives - To evaluate the impact of the Health Education Authority's 20 hour Look After Your Heart health promotion course on a large group of retired women.

Design - Three groups of retired women were compared: group 1 women, drawn from 12 retirement groups, participated in the programme; group 2 , drawn randomly from the same groups, declined; group 3, selected randomly from 12 different retirement groups matched for geographical area, were not offered the course.
\end{abstract}

Setting - Twenty four retirement groups established by a major national retail company in England.

Subjects - A total of 739 women with a mean age of 66 years participated. Altogether 200 women were in group 1,192 in group 2, and 347 in group 3.

Main outcome measure - The Nottingham Health Profile was administered and exercise knowledge, attitudes, and behaviour of the three groups were assessed using a validated, reliable questionnaire.

Results - Group 1 had significantly better self-perceived health, indicated by lower Nottingham Health Profile scores, more exercise knowledge, and positive exercise attitudes and they did more exercise than the other two groups. The responses of groups 2 and 3 were similar. Time since completion of the programme did not have any effect on Nottingham Health Profile scores, exercise knowledge, and behaviour.

Conclusion - The Look After Your Heart programme is associated with beneficial and persistent effects in retired women. Detailed studies are needed to confirm whether these associations are due to the programme or reflect the selection of fitter, healthier subjects.

( $\mathcal{F}$ Epidemiol Community Health 1994;48:123-128)

Exercise provides a needed stimulus for the maintenance of structural and functional integrity of the cardiorespiratory system,,$^{1-2}$ the locomotor system, ${ }^{3-5}$ and probably the autonomic nervous system and motor neurons. ${ }^{6}$

The risks of developing chronic illness and disability in old age may be prevented and alleviated by adopting a more physically active lifestyle. ${ }^{7-9}$ With greater functional fitness more activities of daily living can be performed efficiently within the working capacity of the individual, ${ }^{10}$ and some of the decline in physical capacity which seems to occur with, rather than because of ageing, ${ }^{11}$ may be alleviated.

Evaluation of the psychological changes and quality of life associated with exercise participation is also of interest. Potential mechanisms that mediate improvements in wellbeing are thought to involve enhanced feelings of mastery and physiological changes from increases in brain and plasma opioid concentrations. ${ }^{12}$

It is possible that people will only benefit from exercise if it is performed vigorously for 20 minutes at least three times per week. ${ }^{13}$ For older people a more modest intensity and frequency of exercise may be beneficial. Customary activities such as regular brisk walking may be of use in the prevention of stroke ${ }^{14}$ and osteoporosis ${ }^{1516}$ and are closely correlated with unspecific symptoms. ${ }^{9}$

The recent health policy initiative, the Health of the Nation, will rely on improving the health behaviour of large sections of the population, particularly the "young elderly" who have a high risk of cardiovascular disease, to achieve reduced mortality targets. ${ }^{17}$ Increased physical activity and exercise are key strategies that are expected to play a part in reducing the risk of cardiovascular disease. Exercise remains a minority pursuit for people in general and older women in particular, ${ }^{418}$ and levels of customary physical activity are also low. ${ }^{19}$

The Health Education Authority has developed the national health promotion course Look After Your Heart ${ }^{20}$ in response to the low exercise participation rates and the link between exercise and coronary heart disease. The programme is taught for two hours a week by a trained Health Education Authority teacher and lasts for 10 weeks. The course combines both exercise theory and practice. The programme consists of three parts: risk factors associated with heart disease, how to exercise regularly in a safe way, and how to cope with stress.

Look After Your Heart courses have received little evaluation of effectiveness. To date, only one small scale study has been conducted to assess the programme's effects on elderly people. ${ }^{21}$ The present study aimed to evaluate the programme's effects on self-perceived health status, exercise knowledge, attitudes, and behaviour on a large group of retired women. 
Subjects and methods

The subjects were 739 women in England who were retired employees of a major British retail company and belonged to their local retirement association. The women formed three groups: group 1 comprised 200 women from 12 retirement associations who had taken part in a Look After Your Heart course. Group 2 comprised 192 women randomly selected from the same 12 retirement associations who had been invited to attend a course but had declined the invitation. Group 3 comprised 347 women who were randomly selected from 12 different retirement associations whose members had not been invited to attend a course and whose retirement areas, which were the same as their working areas for most women, matched the area social deprivation scores of the other 12 groups. $^{22}$

The Nottingham Health Profile (NHP) was used to measure self-perceived health status. Part 1 asks about current health in six dimensions - energy, pain, emotional reactions, sleep, social isolation, and physical mobility. Part 2 is concerned with whether health is causing problems with everyday activities such as looking after the home, sex life, hobbies, and holidays. Respondents are asked to give a "yes/ no" answer to each item. The NHP was sent by post with up to two repeat mailings. It was scored conventionally using the published item weights giving a score ranging from 0 to 100 on each dimension of part 1. Part 2 scores were obtained by simply presenting the proportions of respondents checking "yes" to each item. The distributions of NHP scores were presented using mean (SD) for convenience and comparability with reference standards but appropriate non-parametric statistical tests were carried out. The NHP is a valid and reliable tool for measuring health status, particularly in older people. ${ }^{23}$

Reference population values (means only were reported) for 2173 women aged 65-69 years were obtained from published data on a random sample of people registered with general practitioners in the Nottingham area. ${ }^{23}$

LONDON HEALTH AND FITNESS QUESTIONNAIRE All women were sent the London Health and Fitness Questionnaire (LHFQ) through the post. The questionnaire was developed for this and other studies of physical activity in older people. It was derived from initial in depth interviews to define key areas of importance which were held with selected groups of elderly people attending a local Age Concern advice office and a lunch club. A questionnaire suitable for postal administration was derived from these in depth interviews and was organised into a series of questions about exercise behaviour and knowledge and additional attitude questions were taken from the Allied Dunbar National Fitness Survey ${ }^{18}$ (J N Morris, personal communication). The LHFQ measured peoples' exercise knowledge using a series of positive and negative statements. Attitudes towards exercise were measured using a five point Likert scale and results were pre- sented as the proportions agreeing and agreeing strongly with specific statements. Exercise behaviour was measured as the amount of time spent in the previous week on domestic activity (for example, gardening, housework), and sport/recreational activity (for example, walking, cycling, and swimming). This was categorised into time intervals of no time at all, less than one hour, less than two hours, less than three hours, and three or more hours and the approximate time (in hours) was computed as the mid-point of each category interval. Very few subjects indicated that they spent more than three hours in specific activities and in these cases a value of four hours was assumed.

The questionnaire was then tested in a random sample of 130 women of pensionable age drawn from the age-sex register of a group practice in Wapping, east London. Up to two further mailings were sent to non-respondents. A sample of 30 respondents was visited and the questionnaire re-administered by an interviewer two weeks after the postal return. A sample of 83 women aged 67 years (range 6089) responded. Kappa coefficients of testretest agreement between postal and interview administration were acceptable but were lowest for knowledge items and highest for exercise behaviours. Kappa values are shown in table 1 . The correlations between hours spent in domestic activity and sporting/recreational activity were high, 0.92 and 0.76 respectively. The mean (SD) differences in hours between postal questionnaire and interview assessments for the domestic and sporting/recreational activity were $-0.6(2 \cdot 2) \mathrm{h}$ and $0 \cdot 1(1 \cdot 4) \mathrm{h}$ respectively, indicating excellent agreement between the two measurement occasions.

Construct validity was examined by comparing the exercise behaviours, knowledge, and attitudes in subjects who went out daily and those who did not, those less than and older than the average age of the sample, and those who said they did and did not take a daily brisk walk. More positive knowledge and attitudes towards exercise and more participation in all forms of regular exercise were apparent in those subjects who went out each day, those who were younger, and those who took a daily brisk walk (see table 2).

\section{APPLICATION TO MAIN STUDY SUBJECTS}

Group 1 participants were written to after they had finished the Look After Your Heart course. The median duration between course

Table 1 Concordance between responses from self-completed and interview administered versions of the London Health and Fitness Questionnaire

\begin{tabular}{ll}
\hline Topic & Kappa \\
\hline Perceived health and fitness: & \\
Self assessed health & 0.63 \\
Self assessed fitness & 0.56 \\
Could walk a mile & 0.83 \\
Activities undertaken: & \\
Going out of the home & $1 \cdot 00$ \\
Walking 20-30 minutes a day & 0.54 \\
Organised activity & $1 \cdot 00$ \\
Social activity & 0.79 \\
Knowledge/attitudes: & 0.22 \\
Do you exercise enough to keep fit? & 0.45 \\
Is exercise beneficial in old age? &
\end{tabular}


attendance and questionnaire completion was 10 months, with a range of three to 20 months. Non-respondents were sent a second questionnaire six weeks later. It was not possible to obtain measurements on subjects before starting the programme since the investigators were only involved in assessing the impact of the course after it had been introduced by some retirement associations. Other associations were uncertain about using the package

Table 2 Construct validity of London Health and Fitness Survey

\begin{tabular}{|c|c|c|c|c|c|c|c|c|}
\hline & \multicolumn{2}{|c|}{$\begin{array}{l}\text { Organised } \\
\text { activity }\end{array}$} & \multicolumn{2}{|c|}{$\begin{array}{l}\text { Going out } \\
\text { daily }\end{array}$} & \multicolumn{2}{|c|}{$\begin{array}{l}\text { Daily brisk } \\
\text { walk }\end{array}$} & \multicolumn{2}{|c|}{ Age (y) } \\
\hline & Yes & No & Yes & No & Yes & No & $<69$ & $70+$ \\
\hline \multicolumn{9}{|c|}{$\begin{array}{l}\text { Self assessed health and fitness } \\
(\%):\end{array}$} \\
\hline Good/average health & 78 & 45 & 52 & 33 & 48 & 48 & 52 & 46 \\
\hline Very/fairly fit & 100 & 76 & 89 & 44 & 91 & 59 & 86 & 72 \\
\hline Able to walk a mile & 80 & 43 & 60 & 0 & 62 & 18 & 61 & 28 \\
\hline Do enough exercise & 80 & 59 & 69 & 27 & 69 & 46 & 61 & 61 \\
\hline \multicolumn{9}{|l|}{ Duration of activity $(h)$ : } \\
\hline Domestic activity & $8 \cdot 1$ & 6.5 & $9 \cdot 8$ & $3 \cdot 2$ & 11.5 & $6 \cdot 2$ & $8 \cdot 4$ & $4 \cdot 7$ \\
\hline Sport/recreational & $3 \cdot 3$ & $1 \cdot 2$ & $2 \cdot 4$ & $0 \cdot 8$ & 3.9 & $1 \cdot 1$ & 3.5 & $2 \cdot 2$ \\
\hline \multicolumn{9}{|l|}{ Attitudes ( $\%$ agreeing): } \\
\hline I'm not the sporty type & 33 & 65 & 60 & 64 & 50 & 63 & 64 & 58 \\
\hline I haven't got the time & 22 & 33 & 33 & 25 & 33 & 27 & 38 & 19 \\
\hline I'm too old & 0 & 40 & 21 & 80 & 21 & 59 & 16 & 65 \\
\hline stops me & 11 & 50 & 34 & 85 & 39 & 55 & 34 & 60 \\
\hline I haven't got the energy & 10 & 59 & 40 & 92 & 40 & 74 & 41 & 67 \\
\hline
\end{tabular}

Table 3 Comparison of mean (SD) Nottingham Health Profile scores (part 1) for groups 1, 2, and 3 and percentage of affirmative responses (ie with problems) for part 2. Reference population values are given as means only ${ }^{23}$

\begin{tabular}{|c|c|c|c|c|}
\hline & $\begin{array}{l}\text { Group } 1 \\
(n=190)\end{array}$ & $\begin{array}{l}\text { Group 2 } \\
(n=183)\end{array}$ & $\begin{array}{l}\text { Group } 3 \\
(n=331)\end{array}$ & $\begin{array}{l}\text { Reference } \\
\text { population }\end{array}$ \\
\hline \multicolumn{5}{|c|}{ Part 1 (mean (SD) score): } \\
\hline Energy & $\begin{array}{c}8 \cdot 2^{*} \\
(19 \cdot 6)\end{array}$ & $\begin{array}{c}15 \cdot 2 \\
(28 \cdot 6)\end{array}$ & $\begin{array}{c}14 \cdot 5 \\
(28 \cdot 4)\end{array}$ & $23 \cdot 6$ \\
\hline Pain & $\begin{array}{c}6 \cdot 8^{*} \\
(19 \cdot 1)\end{array}$ & $\begin{array}{l}11.5 \\
(22.5)\end{array}$ & $\begin{array}{c}10 \cdot 2 \\
(21 \cdot 8)\end{array}$ & $20 \cdot 9$ \\
\hline Emotions & $\begin{array}{c}5.6 \\
(11.9)\end{array}$ & $\begin{array}{c}9 \cdot 0 \\
(18 \cdot 8)\end{array}$ & $\begin{array}{c}7 \cdot 0 \\
(16 \cdot 2)\end{array}$ & $12 \cdot 5$ \\
\hline Sleep & $\begin{array}{c}17 \cdot 5 \\
(24 \cdot 6)\end{array}$ & $\begin{array}{c}23.0 \\
(28.4)\end{array}$ & $\begin{array}{c}22 \cdot 0 \\
(28 \cdot 2)\end{array}$ & $38 \cdot 5$ \\
\hline Isolation & $\begin{array}{c}2 \cdot 9 \\
(9 \cdot 6)\end{array}$ & $\begin{array}{c}5 \cdot 5 \\
(14 \cdot 9)\end{array}$ & $\begin{array}{c}4 \cdot 6 \\
(13 \cdot 6)\end{array}$ & 5.9 \\
\hline Mobility & $\begin{array}{c}4 \cdot 5^{* *} \\
(10 \cdot 5)\end{array}$ & $\begin{array}{c}10 \cdot 5 \\
(18 \cdot 1)\end{array}$ & $\begin{array}{c}8.0 \\
(15 \cdot 5)\end{array}$ & $18 \cdot 0$ \\
\hline \multicolumn{5}{|c|}{ Part 2 ( $\%$ affirmative responses): } \\
\hline $\begin{array}{l}\text { Paid work } \\
\text { Housework }\end{array}$ & $\begin{array}{l}0 \cdot 5 \\
8 \cdot 6^{* *}\end{array}$ & $\begin{array}{r}1.5 \\
19 \cdot 4\end{array}$ & $\begin{array}{r}2 \cdot 8 \\
15 \cdot 8\end{array}$ & $\begin{array}{r}8 \cdot 2 \\
28 \cdot 8\end{array}$ \\
\hline Social life & $3 \cdot 5^{* *}$ & 11.8 & 11.0 & $20 \cdot 5$ \\
\hline Home life & $3 \cdot 0$ & $6 \cdot 7$ & $7 \cdot 3$ & $6 \cdot 8$ \\
\hline Sex life & $3 \cdot 6$ & $7 \cdot 3$ & $7 \cdot 6$ & $15 \cdot 1$ \\
\hline Interests & $8 \cdot 2^{*}$ & $17 \cdot 4$ & $13 \cdot 0$ & $19 \cdot 2$ \\
\hline Holidays & $5 \cdot 0$ & $10 \cdot 7$ & $10 \cdot 4$ & $19 \cdot 2$ \\
\hline
\end{tabular}

Kruskal-Wallis ANOVA for part 1 and $\chi^{2}$ for part $2:{ }^{*} \mathrm{pR} 0 \cdot 05 ;{ }^{* *} \mathrm{p} \mathbb{R} 0 \cdot 001$.

Table 4 Percentage of subjects correctly responding to statements about exercise knowledge in the three groups

\begin{tabular}{llllc}
\hline Statement & $\begin{array}{l}\text { Group 1 } \\
(n=190)\end{array}$ & $\begin{array}{l}\text { Group 2 } \\
(n=183)\end{array}$ & $\begin{array}{l}\text { Group 3 } \\
(n=331)\end{array}$ & $\varkappa^{2}$ \\
\hline Exercise can: & & & & \\
1 Prevent heart disease & 90 & 84 & 85 & $4 \cdot 2$ \\
2 Develop body strength & 89 & 85 & 88 & $1 \cdot 4$ \\
3 Help you lose weight & 77 & 79 & 78 & $0 \cdot 3$ \\
4 Release stress & 98 & 88 & 87 & $19 \cdot 0^{* *}$ \\
5 Help you relax & 97 & 88 & 89 & $12 \cdot 4^{* *}$ \\
6 Help you make friends & 92 & 83 & 83 & $8 \cdot 9^{* *}$ \\
7 Give you energy & 83 & 68 & 75 & $11 \cdot 3^{* *}$ \\
8 Keep you supple & 98 & 94 & 94 & $5 \cdot 9^{*}$ \\
9 Get you outdoors & 97 & 96 & 96 & $0 \cdot 4$ \\
10 Make you feel good & 97 & 90 & 92 & $7 \cdot 3^{*}$ \\
11 Improve health & 98 & 94 & 95 & $5 \cdot 1$ \\
12 Give you aches/pains & 79 & 71 & 72 & $3 \cdot 9$ \\
13 Weaken your bones & 96 & 94 & 93 & $1 \cdot 9$ \\
15 Shrease blood pressure & 94 & 88 & 91 & $3 \cdot 6$ \\
16 Be not much fun & 99 & 97 & 95 & $5 \cdot 2$ \\
17 Make you depressed & 87 & 73 & 78 & $10 \cdot 7^{* *}$ \\
\hline
\end{tabular}

${ }^{*} \mathrm{p}<0.05 ; * * \mathrm{p}<0.01$.

Note: questions $1-11$ were answered correctly with agreement, questions $12-17$ by disagreement. and wanted evidence of effectiveness. It was hoped that a comparison of those who had and had not completed or been offered the programme might give some guidance for these retirement associations.

\section{STATISTICAL ANALYSIS}

The Kruskal-Wallis one way analysis of variance (ANOVA) and $\chi^{2}$ test were used to compare the responses of the three groups on NHP scores and exercise knowledge and attitude questions. Time spent on exercise was calculated in hours and an ANOVA was used to compare the three groups.

\section{Results}

Responses in groups 1, 2, and 3 were $93 \%$, $91 \%$, and $88 \%$ respectively. This gave an overall postal response rate of $90 \%$ (739 women). Thirty five of these questionnaires contained a large amount of missing data and could not be used, which left a total of 704 women actively involved in the study.

The mean (SD) ages of the women in groups 1,2 , and 3 were 65 (6) years, $67(8)$ years, and 66 (8) years respectively. Most women had worked for the company as sales assistants $80 \%, 70 \%$, and $77 \%$ in groups 1,2 , and 3 respectively. In all three groups, over $90 \%$ of the sample population had left school at the age of 14 years, and over $80 \%$ had left school without any formal educational qualifications at all.

The three groups did not differ in their ratings of overall health and fitness. Most elderly women believed they were in "excellent" or "good" health $(77 \%, 72 \%$, and $69 \%$ in groups 1,2 , and 3 respectively and that they were "very" or "fairly" fit $(95 \%, 88 \%$, and $90 \%$ in groups 1,2 , and 3 respectively).

\section{NHP SCORES}

Table 3 illustrates the mean (SD) score and the significance of the group differences on the NHP. Group 1 had significantly better wellbeing scores than the other two groups for the energy, pain, and physical mobility dimensions of the NHP. The scores for groups 2 and 3 were similar and higher. Group 1 reported fewer problems on part 2 of the NHP, while groups 2 and 3 reported similar and higher scores. The reference population of elderly women and groups 2 and 3 had similar or higher NHP scores, suggesting that the study subjects were broadly representative of a community sample of older women.

\section{EXERCISE KNOWLEDGE}

The level of exercise knowledge for the women in all three groups was high (table 4). The knowledge of groups 2 and 3 was consistently less accurate than that of group 1 on all questions except one (question 3 ). 
Table 5 Percentage of subjects agreeing with positive exercise attitude statements

\begin{tabular}{llllc}
\hline Attitude & $\begin{array}{l}\text { Group 1 } \\
(n=190)\end{array}$ & $\begin{array}{l}\text { Group 2 } \\
(n=183)\end{array}$ & $\begin{array}{l}\text { Group 3 } \\
(n=331)\end{array}$ & $\chi^{2}$ \\
\hline 1 Not the "sporty" type & 64 & 73 & 73 & $5 \cdot 9^{*}$ \\
2 Not got the time & 27 & 32 & 33 & $2 \cdot 0$ \\
3 Too shy & 17 & 15 & 24 & $7 \cdot 2^{*}$ \\
4 No one to do it with & 37 & 41 & 41 & $19 \cdot 4^{* *}$ \\
5 Too old & 12 & 24 & 29 & $0 \cdot 9$ \\
6 No local facilities & 19 & 20 & 19 & $6 \cdot 1^{*}$ \\
7 Health is not good enough & 19 & 28 & 29 & $14 \cdot 0^{* *}$ \\
8 Need to relax in spare time & 36 & 50 & 51 & $11 \cdot 3^{* *}$ \\
9 Might damage health & 15 & 26 & 30 & $0 \cdot 2$ \\
10 Don't enjoy exercise & 18 & 31 & 31 & $5 \cdot 9^{*}$ \\
11 Haven't got the equipment & 63 & 70 & 70 & $7 \cdot 1^{*}$ \\
12 Wouldn't keep it up & 41 & 51 & 52 & $0 \cdot 8$ \\
13 Too fat & 18 & 20 & 26 & \\
14 Can't afford it & 21 & 27 & 32 & \\
15 Not very good at sport & 65 & 70 & 69 & \\
\hline * & & & &
\end{tabular}

\section{EXERCISE ATTITUDES}

Table 5 shows the differences in attitude between the three groups. Compared with the women in group 1, the women in groups 2 and 3 were more likely to report negative attitudes. The attitudes which groups 2 and 3 expressed were strikingly similar on all questions.

\section{EXERCISE BEHAVIOUR}

There were no significant differences between the groups in the amount of time spent each week on domestic activities such as housework, gardening, and shopping. All groups spent about 13 hours a week on this type of activity (table 6). However, group 1 women spent approximately one hour more $(p<0.001)$ on sport or recreational exercise (walking, cycling, and swimming) each week than the other two groups.

\section{TIME SINCE PROGRAMME COMPLETION}

Since it was impossible to standardise the time from the Look After Your Heart course to questionnaire completion, the responses given by group 1 subjects were stratified by the median time since course completion (10 months) and compared. There were no significant differences in NHP scores, knowledge, and behaviour between group 1 subjects who completed the questionnaire after the median time of 10 months and those who had completed it more recently. There were significant differences $(p<0.01)$ for three of the attitude items with more recent completers having more positive attitudes to statements: "I cannot afford to exercise", "I am too old to exercise", and "my health is not good enough".

Table 6 Mean number of hours spent on domestic activity and sport/recreational exercise per week by groups 1, 2, and 3

\begin{tabular}{|c|c|c|c|c|}
\hline & No of $h$ & $($ mean $(S D))$ & F ratio & $p$ \\
\hline \multicolumn{5}{|c|}{ Domestic activity: } \\
\hline $\begin{array}{l}\text { Group } 1 \\
\text { Group } 2 \\
\text { Group } 3\end{array}$ & $\begin{array}{l}13.3 \\
13.1 \\
12.5\end{array}$ & $\begin{array}{l}3.6 \\
4.5 \\
3.9\end{array}$ & $2 \cdot 1$ & $0 \cdot 11$ \\
\hline \multicolumn{5}{|c|}{ Sport/recreational activity: } \\
\hline $\begin{array}{l}\text { Group } 1 \\
\text { Group } 2 \\
\text { Group } 3\end{array}$ & $\begin{array}{l}5 \cdot 0^{*} \\
3 \cdot 9 \\
4 \cdot 1\end{array}$ & $\begin{array}{l}2 \cdot 7 \\
2 \cdot 6 \\
2 \cdot 7\end{array}$ & $9 \cdot 5$ & $<0.001^{*}$ \\
\hline
\end{tabular}

\section{Discussion}

Members of group 1 who attended the health promotion course showed that they had significantly better NHP scores, more exercise knowledge, more positive attitudes towards exercise, and spent more time on "sporty" exercise per week than members of groups 2 and 3. The control groups - group 2 (who declined the course) and group 3 (who were not invited to attend) - gave very similar NHP, knowledge, attitude, and exercise behaviour responses.

The NHP is a well established method of examining self-perceived health status and the differences shown between group 1 and the other groups may be interpreted as a beneficial impact of the Look After Your Heart programme on health status. Because the scores on the NHP were not normally distributed, the SDs are not interpretable but are given for comparative purposes with other studies.

The LHFQ is a new instrument designed for this and other studies of the levels of exercise knowledge, attitudes, and behaviour. It was necessary to develop a new instrument because existing approaches were unsuitable for postal administration ${ }^{19}$ and no other instrument could be found. The attitude section was taken from the National Fitness Survey interview schedule which had been developed with some care. ${ }^{18}$ We have carried out some reliability and validity testing in older people and have found good evidence of repeatability when the test is applied by post and by interviewer two weeks later. Construct validity was also consistent with expectations. We are confident that the questionnaire is capable of giving reliable and valid measures of exercise behaviour, attitudes, and knowledge. The questionnaire will undoubtedly benefit from further development and performance testing and copies are available from the investigators.

In this observational study it is possible that a selection bias produced by healthier and fitter subjects volunteering to attend the course has occurred. The comparison with group 2 subjects cannot exclude selection bias as the explanation for the better group 1 findings. However, group 3 consisted of people who had not been offered the course and therefore comprised women typical of the whole retired population. In addition, groups 2 and 3 had similar or lower NHP scores to the reference sample of women suggesting a small "healthy retired worker" effect. Special effort was made to match the groups for Jarman deprivation scores to avoid making a comparison potentially biased by north-south or socioeconomic differences. Since the group 2 and 3 results were similar this suggests that major selection bias is an unlikely explanation of the findings and that it is more likely that the course had a positive effect on group 1 women.

Observational studies can never prove causation but can provide supporting evidence of association. Ideally, a randomised controlled trial of the impact of a health promotion programme should be set up but the practical problems of conducting trials of exercise are considerable. A health promotion programme 
can never be double-blind and it is almost impossible to blind the assessors to the intervention. It is difficult to standardise the intervention, to force subjects to take part, and to avoid contamination effects in the control group as a result of media and public health campaigns. Furthermore, given the current levels of evidence supporting exercise it is unlikely that an untreated control group would be ethically permissable. For these reasons large randomised controlled trials of the effects of exercise have never been set up.

It would have been preferable to make measurements both before and after the 10 week programme in group 1 women, and to make two assessments of health status and exercise profiles of subjects in groups 2 and 3 at baseline and 10 weeks. This was not feasible since subjects in group 1 had all completed the course before the investigation was started. Moreover, it would have been impossible to examine the duration of effect without making further measurements over a longer period. This study provides the only evidence to support a possible beneficial impact of the national Look After Your Heart programme. Inevitably, it is impossible to exclude selection bias as the explanation for our findings but this would have to be considerable to explain the differences observed.

The national sample used in this study precluded the objective assessment of physical fitness. However, small scale studies have shown that the intensity and frequency of exercise recommended by the programme is unlikely to have a large effect on physical capacity. ${ }^{21}$ This is not necessarily a disadvantage of the programme as it intends to promote exercise, getting people started, rather than providing a definitive, life long programme. Furthermore, it is likely that the intensity and frequency of exercise required for improving physical capacity may be higher than that required for reducing disease risk and improvements in wellbeing.

One of the drawbacks of health promotion courses is that their effects are thought to be only short lived. ${ }^{24}$ However, the positive results shown by group 1 suggest that the effects of this programme may be long term, since the average time of course completion was 10 months. The results of this and other work ${ }^{21}$ also show the ability of older people to modify their health behaviours.

Previous studies of the impact of exercise on quality of life and self-perceived health have reported conflicting results with benefits claimed for exercise in improving mood and locus of control ${ }^{25-27}$ and no benefit in others. ${ }^{28-30}$ These different findings are probably explained by methodological weaknesses such as the lack of appropriate control groups, poor standardisation of exercise interventions and the limited range of outcomes considered.

Knowledge about exercise was good among all the women in this study, despite the fact that most had left school at the age of 14 years, with very little formal education. The main concerns of all groups were that they perceived themselves as not being very good at sport, as not being the "sporty" type, and as not having the necessary equipment for it. This study and other work suggests that elderly people's lack of involvement in exercise is the result of inappropriate age stereotypes, the limited exercise experiences of older people while at school, ${ }^{31}$ and beliefs that exercise is harmful to health. ${ }^{32}$ Health promotion interventions need to explain the myths about physical activity and move away from the image of portraying "sport" as being the major beneficial form of exercise for older people.

Active participation in exercise as experienced by group 1 women through their course seems to promote factual knowledge of exercise and a qualitative, realistic understanding of exercise. This seems to have encouraged group 1 subjects to take exercise, outside of everyday activities, in the form of recreational exercise. Other health promotion studies confirm the importance of participation for behavioural change. . $^{33} 34$

A theory which is supported by our data has been developed recently by Weinstein. ${ }^{35}$ It is a five stage theory of ordered preventive behaviour called the "precaution adoption process". In stage 1 , a person has heard about a health hazard (for example that inactivity can cause coronary heart disease); at stage 2 the person believes that the health problem is important for other people; by stage 3 the personal susceptibility to the health hazard is admitted; at stage 4 preventive action is started; and stage 5 is where the person actually maintains the preventive action. Health promotion courses need to tackle these stages systematically.

Further research is needed if participation in exercise is to be improved. More data of knowledge, attitudes, and behaviour is needed on other groups of women and men who have reached retirement age. Since older people suffer the greatest burden of cardiovascular disease it will be essential that they are included in primary prevention strategies, such as exercise, stopping smoking, blood pressure control, and dietary change, that have an impact over a relatively short time period. It would be unfortunate if older people were ignored on the grounds that they are too old to change or that avoiding disease is not worthwhile in older age. Further work on the benefits and risks of different intensities and frequencies of exercise regimes would lead to better "exercise prescriptions" for older people.

This work was supported by Marks and Spencer plc, PPP Trust, the London Hospital Medical College and a grant from the Health Education Authority.

1 Sidney KH, Shepherd RJ. Frequency and intensity of exercise training for elderly subjects. Med Sci Sports 1978;10:125-31.

2 Stevenson JS, Topp R. Effects of moderate and low intensity long-term exercise by older adults. Res Nurs Health 1990;13:209-18.

3 Grimby G. Physical activity and muscle training in the elderly. Acta Med Scand 1986;711(Suppl):233-7.

Hardman AE. Benefits of low intensity exercise in women. Sports Medicine and Soft Tissue Trauma 1991;3(1):14-15. Simpson WM. Exercise: prescriptions for the elderly. Geriatrics 1986;41(1):95-100.

6 Holloszy JO. Exercise, health, and aging: a need for more information. Med Sci Sports Exerc 1983;15(1):1-5.

Gloag D. Exercise, fitness, and health. BMf 1992;305:3778 . 
8 Fentem PH, Bassey EJ, Turnbull NB. The new case for exercise. London: Health Education Authority, 1988.

9 Ebrahim S, Dallosso HM, Morgan K, Fentem PH, Arie T The causes of handicap among a random sample of old and very old people: possibilities for prevention. $\mathcal{f} R$ Coll Physicians Lond 1988;22:105-7.

10 Gray JAM, Bassey EJ, Young A. The risks of inactivity. In: Gray JAM, ed. Prevention of disease in the elderly. Edinburgh: Churchill Livingstone, 1985:78-94.

11 Posner JD, Gorman BS, Howard SK, Woldow A. Exercise capacity in the elderly. Am $\mathcal{f}$ Cardiol 1986;57:52-8.

12 Veale DMW de C. Exercise and mental health. Acta Psych Scand 1987;76:113-30.

13 Morris JN, Clayton DG, Everitt MG, Semmence AM, Burgess EH. Exercise in leisure time: coronary attacks and death rates. Br Heart $\mathcal{F}$ 1990;63:325-34.

14 Wannamethee G, Shaper AG. Physical activity and stroke in British middle aged men. BMF 1992;304:597-601.

15 Krolner B. Physical exercise as a prophylaxis against invorolner B. Physical exercise as a prophylaxis against invo-
lutional vertebrae bone loss: a controlled trial. Clin Sci 1983;64:541-6.

16 Prince RL, Smith M, Dick I, et al. Prevention of postmenopausal osteoporosis: a comparative study of exercise, calcium supplementation, and hormone replacement therapy. N Engl f Med 1991;325(17):1189-95.

17 Secretary of State for Health. The health of the nation. London: HMSO, 1991.

18 Activity and Health Research. Allied Dunbar national fitness survey: a report on activity patterns and fitness levels. Main findings. London: Sports Council and Health Education Authority, 1992.

19 Dallosso HM, Morgan K, Bassey EJ, Ebrahim S, Fentem PH, Arie THD. Levels of customary physical activity among the old and the very old living at home. $\mathcal{F}$ Epidemiol Community Health 1988;42:121-7.

20 Health Education Authority. Beating heart disease in the 1990s: a strategy for 1990-1995. London: Health Education Authority, 1990 .

21 Ebrahim S, Williams J. Assessing the effects of a health promotion programme for the elderly. $\mathcal{f}$ Public Health Med 1992;14(2):199-205.

22 Jarman B. Identification of under privileged areas. $B M \mathcal{F}$ 1983;286:1705-9.
23 Hunt SM, McEwen J, McKenna SP. Measuring health status. London: Croom Helm, 1986.

24 status. Lond Wilson AL, Lovato CY. What changes can health promotion achieve and how long do these changes health promotion achieve and how long do these changes Prev Med 1986;15:508-21.

25 Emery CF, Blumenthal JA. Perceived change among participants in an exercise program for older adults. Gerontologist 1990;30:516-21.

26 Hudson JI, Manoach DS. The psychological and physiological benefits of passive and aerobic exercise in sedentary middle-aged women. 7 Nerv Ment Dis 1991;179:5734.

27 Bennett J, Carmack MA, Gardner UJ. The effect of a program of physical exercise on depression in older adprogram of physical exercise on dep

28 Blumenthal JA, Emery CF, Madden DJ, George LK, Coleman RE, Riddle MW. Cardiovascular and behavioral effects of aerobic exercise training in healthy older men and women. F Gerontol 1989;44:147-57.

29 Dustman RE, Ruhling R, Russell EM, Shearer DE Bonekat HW, Shigeoka JW. Aerobic exercise training and improved neuro-psychological functioning of older individuals. Neurobiol Aging 1984;5:5-42.

30 Emery CF, Gatz M. Psychological and cognitive effects of an exercise program for community-residing older adults. an exercise program for comm

31 Ostrow A, Dzewaltowski D. Older adults perceptions of physical activity participation based on age-role and sexrole appropriateness. Research Quarterly for Exercise and Sport 1986;57:167-9.

32 Malloney SK, Fallon B, Wittenberg CK. Aging and health promotion. Washington, DC: Public Health Service, Office of Disease Prevention and Health Promotion, 1986.

33 Bettinghaus EP. Health promotion and the knowledgeattitude-behaviour continuum. Prev Med 1986;15:47591 .

34 Crow R, Blackburn H, Jacobs D, et al. Population strategies to enhance physical activity: the Minnesota Heart Health program. Acta Med Scand 1986;711(Suppl):93-112.

35 Weinstein ND. The precaution adoption process. Health Psychol 1988;7(4):355-86. 